\title{
Ambiguity of form: Old and new
}

GERALD H. FISHER ${ }^{1}$

UNIVERSITY OF NEWCASTLE UPON TYNE, ENGLAND

The two-fold appearances of certain two-dimensional spatial patterns are described. While these ambiguous figures have been employed extensively in a variety of experimental studies of perceptual organization, their use extends beyond psychology and reaches back into antiquity. Regrettably, very few examples of such patterns remain available. A more-or-less comprehensive set of well-known ambiguous figures is described and illustrated, including an equi-ambiguous version of the "chalice and faces." An attempt is made to devise new examples of such figures adding to the repertoire of materials available for studying relevant aspects of visual perception.

The most basic of all the processes involved in visual perception operates when the distinction is made between the figural elements of spatial patterns and the background against which they are seen. Many two-dimensional spatial patterns have been employed in studying the modes of organization and operation of perceptual processes. The volume of study reserved for investigation of the nature of the "figure-ground" phenomenon, and for consideration of the possible ways in which it can be manipulated, accounts for the versatility of configurations whose appearances change spontaneously upon sustained observation. Broadly, there are two categories of such forms. Those known as "reversible figures" which are characterized by the Necker (1832) cube and others described as "ambiguous figures," these being exemplified by Rubin's (1915) "chalice and faces."

The perceptual mechanisms involved in the spontaneous structuring and restructuring of both reversible and ambiguous figures are almost certainly closely related. There is an important difference between them, however, which has become obscured in the discussions of these figures made by Rubin, Porter (1938) and many others who have used the terms "ambiguous" and "reversible" in describing them as if they were synonymous. The patterns are similar in that their figural elements are labile and undergo fluctuation. Both may be described as exhibiting ambiguity and each as reversing. But the ambiguous nature of a reversible figure refers to the vantage point from which the subject which it represents appears to be seen, while in relation to an ambiguous figure it is indicative of the subject apparently represented. The form of the Necker cube is ambiguous in the sense that it may be interpreted as an isometric projection of the same form seen from either one of two different vantage points; whereas, the "chalice and faces" may be seen either as a goblet, or as a pair of inward-looking profiles. Thus, the reversible quality of an ambiguous figure refers to the subject seemingly represented when the pattern takes on one formal quality, or the other, while that of a reversible figure refers to the depth aspect assumed by the spatial components of the pattern. When the Necker cube reverses the relative distances of the two square faces appear to change in depth. When alternating, features of ambiguous figures appear to take different appearances, but they remain in the same depth plane.

Upon first exposure the shape and contour elements of an ambiguous figure appear to represent some such obvious and well-defined form as a human face, or an animal. Upon continued observation, however, the whole spatial components of the configuration appear to become completely transformed in a quite dramatic way; whereupon, they are seen to represent an entirely different subject. What is perhaps the most well-known example of a figure of this kind was brought to the attention of psychologists by Boring (1930). Its two alternative and mutually exclusive appearances are such that, when Hill (1915) first prepared it for publication in the magazine "Puck" he gave it the title "My wife and my mother-in-law." Moreover, he deliberately aroused the curiosity of readers by adding beneath it the cryptic comment "They are both in this picture-Find them."
The extensive use made by psychologists of ambiguous figures is such that it seems somewhat remarkable to find that so few examples have become available for experimental purposes. Dallenbach observed that "... Puzzle pictures in which profiles are concealed in the details are of ancient origin. The motif was frequently used by early' Egyptian, Arabian and Indian designers. .." (1951, p. 432) and Fisher pointed out "... that artists, in advance of psychologists, appreciated that changes in the figural features of spatial forms may be induced by suitable juxtaposition of two-dimensional patterns. .." (1967a, p. 328). He referred specifically to the introduction of "hidden forms" into the works of Bonnard and Vuillard, subsequently attempting to trace the development of Salvador Dali's use of this technique and to determine the implications of the examples of duality of form evident in the drawings of Aubrey Beardsley (Fisher, 1968).

The motives for introducing ambiguous elements into two- and three-dimensional forms would clearly merit consideration by psychologists irrespective of the wide use which they have found in the study of the processes involved in perceptual organization. It is regrettable, however, that so many of these figures have been lost. Examples of reversible figures abound in Greek and Roman mosaics. What is perhaps the best example known of these was excavated from the ruins of Pompeii and is now exhibited in the National Museum, Naples. The "stacked cubes" motif incorporated within it has been used frequently in experimental stimulus materials but, as far as we are aware, its origin has not previously been pointed out. Early examples of "hidden figures," in which forms are concealed within others were described by Fernberger (1950) and Carmichael (1951). More recently, Elkind, Koegler and Go (1962) devised a version of a "duck and tree" hidden figure for use in a study of developmental features of perceptual organization. Conventional ambiguous figures, on the other hand, are less easy to find. The search for them grows cold after such grotesque comment of the Victorian era as is exemplified in "All is vanity," an ambiguous drawing of a young girl admiring herself in a dressing-table mirror, the whole form of which changes into a ghostly apparition. It appears to warm again with Plesch's (1953) consideration of the figures concealed within the canvases of Rembrandt but the majority of this work appears to bear little relationship to the intentions of the artist.

Janus-type figures have been used in many cultures, presumably with the hope of enjoying the two-fold patronage of the double headed God. An example of a double profile of this kind was illustrated by Crowley (1952) who found it amongst a collection of antique miniatures. The earliest example of ambiguity of form known to the author is illustrated in Fig. 1a. This is the head of an early First Millenium Mace made in bronze. It has three eyes and three noses; upon first observation a full-face is usually seen.

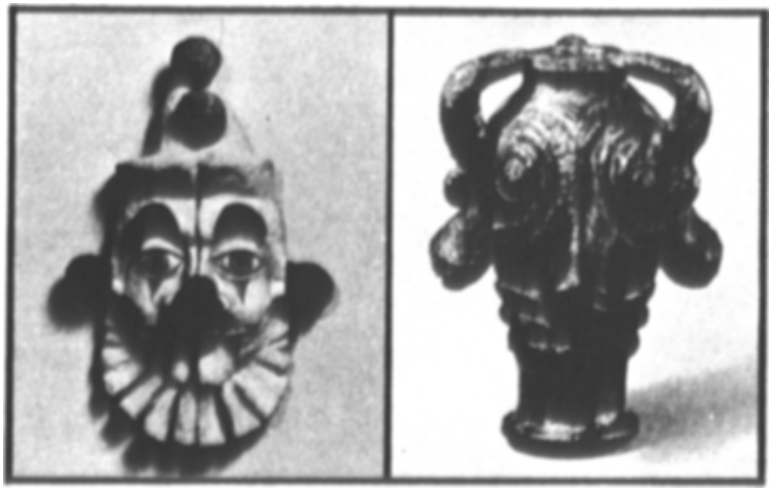

Fig. 1. An early First Millenium B.C. Mace Head and Fisher's threedimensional multiambiguous clown. 
subsequently the two outward-looking profiles becoming apparent. As the mace is rotated each new profile, then the full-face, comes into view. Perhaps the comprehensive protection given by such an all-seeing figure provided a source of comfort for the Iranian foot-soldier who brandished it. Some years before the author discovered this artifact in The Metropolitan Museum of Art, New York, he attempted to prepare a number of multi-aspect ambiguous figures, some of which were illustrated in a definitive study of formal ambiguity $(1967 \mathrm{~b}, \mathrm{p}$. 551). Subsequently, an attempt was made to reproduce these figures in the form of solid models, one of which is illustrated in Fig. Ib. Placed alongside each other, these two photographs serve to illustrate the age and youth of our understanding of visual perception.

The scarcity of ambiguous figures, particularly new ones which have not been widely publicized, has been emphasized by the extremely large number of requests received for reprints of previous papers on this topic. Further, some correspondents have expressed their need of other examples of ambiguous figures. Accordingly, two further sets of materials have been prepared. Illustrated in Fig. 2 is a set of ambiguous figures, most of which are reasonably well-known and some of which have been used in earlier experimental studies. No. 1 was shown by the author (1967c) to be equi-ambiguous in the appearance of the "man and girl;" No. 2 is Hill's version of the "wife and mother-in-law;" No. 3 is Leeper's (1935) original "pirate and rabbit;" Nos. 4, 5, and 6 including respectively a "lion and rose," a "snail and elephant," and a "gypsy and girl" were also shown to be equi-ambiguous by the author (1967b). Botwinick (1961) prepared three versions of a "husband and father-in-law," No. 7 being a reproduction of the one in which he reported both aspects to be equally dominant. No. 8 is detail from Dali's painting entitled "Slave Market with Apparition of the Invisible Bust of Voltaire;" and No. 9 is an equi-probable version of Jastrow's (1900) "duck and rabbit." Traylor's (1965) very unusual, and little known, "nuns and nudes" are reproduced in No. 10; Kolers' (1964) "the boys from Syracuse" in No. 11; and a modified version of Tinbergen's (1951) reversible silhouette which may be seen either as a "goose or hawk" in No. 12. "Yin and Yang," the ancient Chinese monad which symbolizes the basic elements of formal duality, is shown in No. 13. This figure can be developed in innumerable ways, Schafer

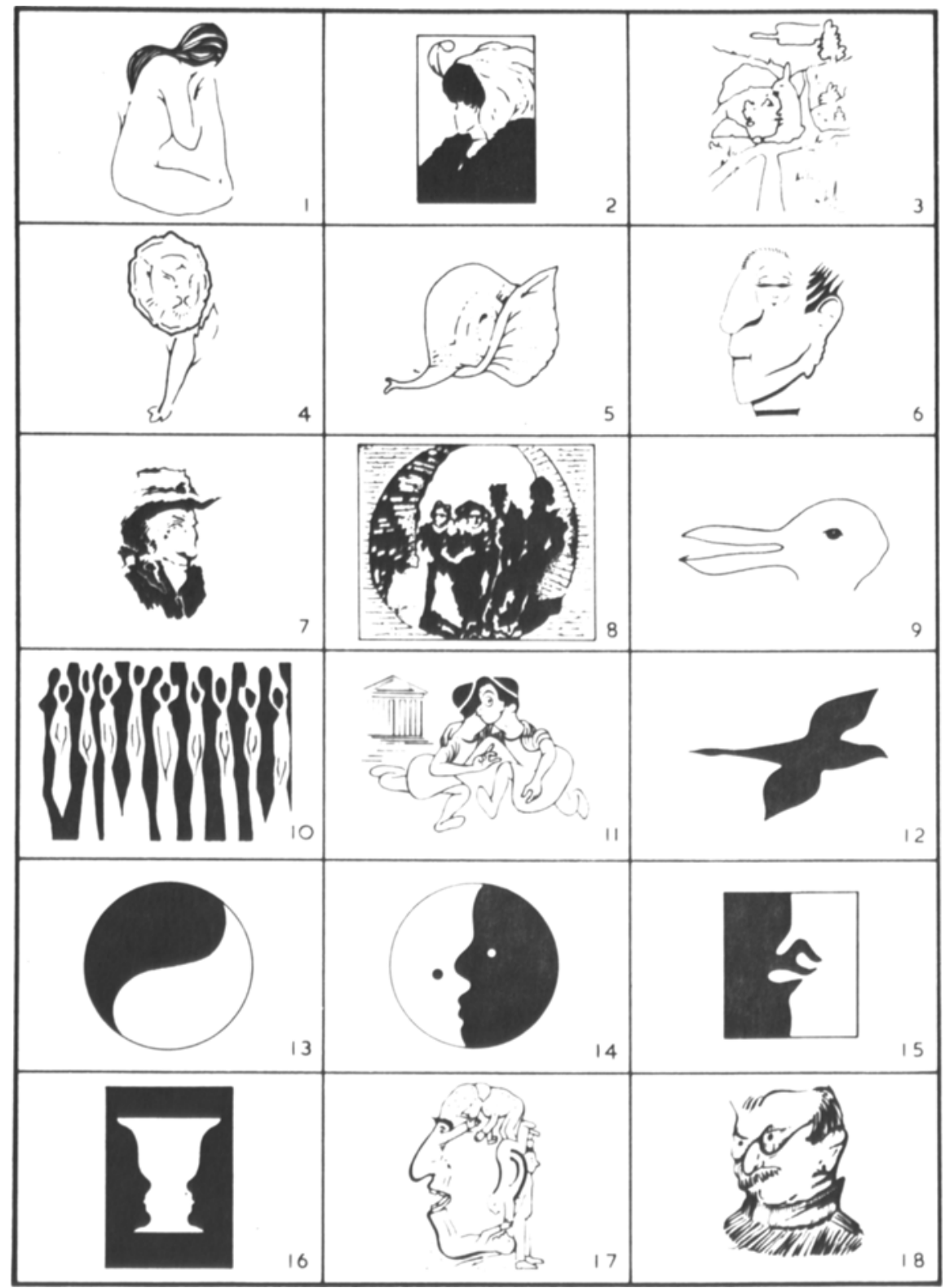

Fig. 2. A set of well-known ambiguous figures. 
and Murphy (1943) having used a "Gog and Magog" form similar to the one reproduced in No. 14. One of Rubin's original figures is illustrated in No. 15 and the modified version of the "chalice and faces" referred to below appears in No. 16. The technique for achievement of ambiguity which is illustrated in the last two figures differs from that described previously. No. 17 is a head composed of several human figures, described by Weigl (1927), to which Dali's treatment of the heads in his painting of "The Great Paranoiac" bears a strong resemblance. No. 18 appeared in Weigl's report on 12th Psychological Congress (1932) held in Jena. The second aspect becomes apparent most readily when the drawing is inverted.

Ambiguous spatial forms of the kind reproduced in Fig. 2 have been used extensively in experimental studies of a variety of features of visual perception. The "wife and mother-in-law" figure, for example, was recommended to the use of experimental psychologists on the grounds that it "... seems to be the best of the puzzle-pictures in the sense that neither figure is favoured over the other..." (Boring, 1930, p. 445). This statement serves to illustrate an extremely important problem which arises when employing ambiguous figures in experimental investigations. This concerns the probability of spontaneous appearance of each of the two embodied spatial elements upon first exposure. Should these fail to be equated in some appropriate way, difficulties arise both in submission of data to analysis and in their interpretation.

The version of the "chalice and faces" figure, reproduced in Fig. 2, No. 16, was prepared subsequent to experiencing failure in the attempt to produce an acceptably equi-ambiguous version of the well-known figure first used by Rubin. Interspersing it with the original set of 15 figures, ranging between the two dominant extremes, and exposing them to a sample of 100 psychologically naive subjects, 58 reported seeing the "chalice" aspect and 42 observed the "faces" in this figure. The mean value of the relevant ideal binomial distribution of probabilities is $100 \times 0.5=50$, its standard deviation being $(100 \times 0.5 \times 0.5)^{1 / 2}=5$. Accordingly, the probability of any particular figure of this kind being truly equi-ambiguous may be determined by considering the extent of departure of distributions of Ss' responses from ideal expectation. The responses of $58 \mathrm{Ss}$ indicated the "chalice" to be seen upon first exposure. This falls at a point on the binomial sampling distribution displaced by 1.6 standard deviations from the mean. The probability of such a value having arisen by chance is

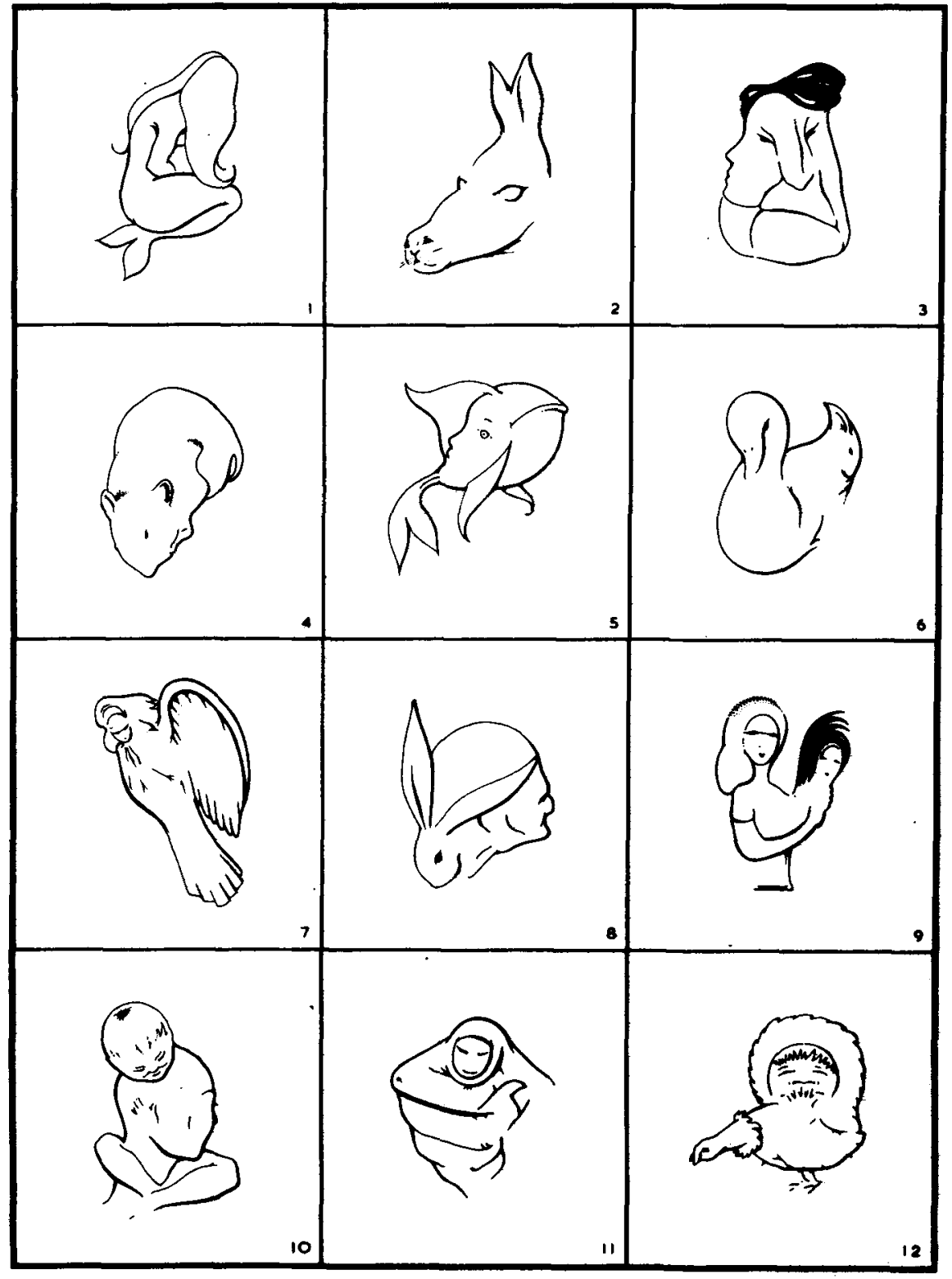

Fig. 3. Newly-devised ambiguous figures. 
approximately 0.11 (two-tail situation). Hence, this figure may reasonably be considered more-or-less equally ambiguous in the appearance of each of its two alternative and mutually exclusive aspects.

Of the ambiguous drawings reproduced in Fig. 2, those numbered $1,4,5,6,9$ and 16 have been shown to be acceptably equi-ambiguous according to the procedures described both here and elsewhere. Extensive studies of the differential appearances of figures of this kind suggests, however, that the perceptual processes involved in distinguishing the figural components of such spatial patterns from the backgrounds against which they are seen undergo modification under even the most subtle influences. Naturally, changes in the spatial characteristics of these patterns will serve to influence the responses made to them and the author will be glad to provide faithful reproductions of the figures illustrated for those who might wish to employ them in further studies. Different presentation procedures, prior exposure to similar patterns, varying degrees of sophistication, set and motivation, age and sex, along with innumerable cognitive, personality and developmental variables, however, have all been shown to be instrumental in modifying the phenomenal attributes of ambiguous spatial patterns also. Accordingly, it should be emphasized that it is mandatory that figures used in testing important hypotheses relating to perceptual organization should be considered carefully in some appropriate study undertaken as a preliminary to any major experiment made with them.

Most of the ambiguous figures illustrated and described above are well-known. In the attempt to prepare figures which are unfamiliar to those who might be used as experimental $S$ s the drawings illustrated in Fig. 3 have been devised. Outside the author's own colleagues and students these ambiguous figures are hitherto unknown and they have not previously been published elsewhere. These drawings have been left unlabeled deliberately. It would be considered both a compliment and a service if those interested in this field of perception were to acquaint the author with the extent to which they succeed in providing suitable alternatives to the classical versions of figures of this kind.

\section{REFERENCES}

BORING, E. G. A new ambiguous figure. Amer. J. Psychol, 1930, 42, 444-445.

BOTWINICK, J. Husband and father-in-law: A reversible figure. Amer. $J$. Psychol., 1961, 74, 312-313.

CARMICHAEL, L. Another hidden-figure picture. Amer. J. Psychol, 1951, 64, 137-138.

CROWLEY, M. E. A puzzle-picture in silhouette. Amer. J. Psychol, 1952, $65,302-304$

DALLENBACH, K. M. A puzzle-picture with a new principle of concealment. Amer. J. Psychol., 1951, 64, 431-433.

ELKIND, D., KOEGLER, R. R., \& GO, E. Effects of perceptual training at three age levels. Science, 1962, 137, 755-756.

FERNBERGER, S. W. An early example of a "hidden figure" picture. Amer. J. Psychol., 1950, 63, 448-449.
FISHER, G. H. Ambiguous figure treatments in the art of Salvador Dali. Percept. \& Psychophys., 1967a, 2, 328-330.

FISHER, G. H. Measuring ambiguity. Amer. J. Psychol, 1967b, 80, 541-557. FISHER, G. H. Preparation of ambiguous stimulus materials. Percept. \& Psychophys, 1967c, 2, 421-422.

FISHER, G. H. Who overlooks "The Fat Woman"? Brit. J. Aesthetics, 1968 (in press).

HILL, W. E. My wife and my mother-in-law. Puck 1915, 6th November, p. 11.

JASTROW, J. Fact and fable in psychology. Boston: Houghton Mifflin, 1900. KOLERS, P. A. The boys from Syracuse: Another ambiguous figure. Amer. J. Psychol., 1964, 77, 671-672.

LEEPER, R. W. A study of a neglected portion of the field of learning: The development of sensory organization. J. genet. Psychol., 1935, 46, 41-75.

NECKER, L. A. Observations on some remarkable phenomena seen in Switzerland; and an optical phenomenon which occurs on viewing of a crystal or geometrical solid. Phil. Mag., 3 ser., 1832, 1, 329-343.

PLESCH, J. The Rembrandts within Rembrandts. Translated by E. FitzgeraId. London: Simpkin Marshall, 1953

PORTER, E. L. H. Factors in the fluctuation of fifteen ambiguous phenomena. Psychol. Rec., 1938, 2, 231-253.

RUBIN, E. Synsopleyede figurer. Copenhagen: Glydendalski, 1915.

SCHAFER, R., \& MURPHY, G. The role of autism in a visual figure-ground relationship. J. exp. Psychol., 1943, 32, 335-343.

TINBERGEN, N. The study of instinct. Oxford: Clarendon Press, 1951.

TRAYLOR, T. Nuns and nudes. In R. Prelisser, Vision in engineering. Inter. Sci. Tech, 1965, 46, 61-66.

WEIGL, E. Zur Psychologie der sogenannten Abstraktionsprocesse. $Z$. $f$. Psychol, 1927, 103.

WEIGL, E. Untersuchungen zur psychischen Umstellbarkeit auf Grund normalpsychologischer und klinischer Befunde. Report on 12th Psychol. Cong., Jena, 1932.

NOTE

1. Address: Department of Psychology, University of Newcastle Upon Tyne, England.

\section{Acknowledgements}

Fig. 1a is reproduced by permission of The Metropolitan Museum of Art, New York, the gift of Mr. and Mrs. J. J. Klejman, 1965.

Figs. 1b, 2:2, 2:4, 2:5, 2:6, 2:7 are reproduced by permission of the Editor, American Journal of Psychology.

Fig. 2:3 is reproduced by permission of The Journal Press, Provincetown, Massachusetts.

Fig. 2:8 is reproduced by permission of John Waddington Ltd., Leeds.

Fig. 2:10 is reproduced by permission of International Science and Technology, New York.

Fig. 2:11 is reproduced by permission of the New York Times.

Fig. 2:12 is reproduced by permission of The Clarendon Press, Oxford.

Fig. 2:14 is reproduced by permission of the Journal of Experimental Psychology.

(Accepted for publication April 16, 1968.) 